\title{
O modelo de dor inflamatória induzida pela carragenina como estratégia para avaliar a ação de drogas sobre a dor miofascial
}

\author{
The carrageenan-induced inflammatory pain model as a tool to assess the action of \\ drugs on myofascial pain
}

Kelvin Borges Rocha de Souza', Luciana Lyra Casais-e-Silva², Marcio Cajazeira Aguiar ${ }^{3^{*}}$

${ }^{1}$ Graduado em Odontologia pelo Centro Universitário Regional da Bahia (UNIRB), Especialista em Implantodontia pelo Centro de Estudos em Odontologia do Brasil (CEOB) e Mestrando do Programa de Pós-graduação em Processos Interativos de Órgãos e Sistemas da Universidade Federal da Bahia (UFBA); ${ }^{2}$ Graduada em Ciências Biológicas pela UFBA, Mestre e Doutora em Fisiologia pela Universidade de São Paulo (USP), Professora Associada da UFBA; ${ }^{3}$ Graduado e Mestre em Odontologia pela UFBA, Doutor em Biologia Celular e Tecidual pela USP, Professor Associado da UFBA

\begin{abstract}
Resumo
A dor miofascial orofacial vem sendo tratada com analgésicos, anti-inflamatórios, relaxantes musculares, fisioterapia, laserterapia e placas oclusais. Contudo, muitas vezes, tais condutas falham em amenizar o quadro doloroso, havendo a necessidade de testar outras estratégias de tratamento. Metodologia: Uma opção para avaliação experimental dessas terapias seria o teste de dor induzido pela carragenina, associado ao teste de avaliação do limiar nociceptivo, originalmente desenvolvido para avaliar a ação de drogas nas patas de roedores. Sendo assim, o presente estudo analisou a nocicepção causada pela carragenina em masseteres de ratos, através do teste de Von Frey, correlacionando-a com alterações teciduais produzidas por esta droga. A carragenina foi injetada no músculo masseter de ratos, enquanto o grupo controle recebeu soro fisiológico. 0 limiar nociceptivo foi mensurado com um analgesímetro digital antes da administração da carragenina e 5 horas, 1, 3 e 7 dias após o seu uso. Decorridos 8 dias da intervenção, os animais foram eutanasiados, sendo seus masseteres encaminhados para processamento histológico e coloração H\&E. Resultados: Observou-se uma diminuição do limiar da resposta nociceptiva em todos os períodos no grupo com carragenina, quando comparado com o grupo controle, havendo diferença estatisticamente significante nas 5 horas. A análise histológica do grupo experimental mostrou a presença de espaços perimisial e endomisial alargados e preenchidos por uma matriz com alguns linfócitos, muitos macrófagos e raros mastócitos. Conclusão: Os resultados indicaram que a associação de uma droga inflamatória com o método Von Frey pode ser uma opção para o estudo do efeito de terapias de dor miofascial.
\end{abstract}

Palavras-chave: Carragenina. Nocicepção. Síndromes da dor miofascial.

\begin{abstract}
Myofascial orofacial pain has been treated with analgesics, anti-inflammatories, muscle relaxants, physiotherapy, laser therapy and occlusal plaques. However, many times, such behaviors fail to alleviate the painful condition, with the need to test other treatment strategies. Methodology: An option for experimental evaluation of these therapies would be the pain test induced by carrageenan associated with the nociceptive threshold assessment test, originally developed to assess the action of drugs on the rodents' feet. Thus, the present study analyzed the nociception caused by carrageenan in rat masseter using the Von Frey test, correlating it with tissue changes produced by this drug. Carrageenan was injected into the masseter muscle of rats, while the control group received saline. The nociceptive threshold was measured with a digital analgesometer before administration of carrageenan and 5 hours, 1, 3 and 7 days after its use. After 8 days of the intervention, the animals were euthanized, and their masseters were sent for histological processing and H\&E staining. Results: There was a decrease in the nociceptive response threshold in all periods in the group treated with carrageenan when compared to the control group, with a statistically significant difference at 5 hours. Histological analysis of the experimental group showed the presence of enlarged perimisial and endomisial spaces, filled by a matrix with some lymphocytes, many macrophages and rare mast cells. Conclusion: Results indicated that the association of an inflammatory drug with the Von Frey method may be an option for studying the effect of therapies on myofascial pain.

Keywords: Carrageenan. Nociception. Myofascial pain syndromes.
\end{abstract}

\section{INTRODUÇÃO}

A dor é uma experiência sensitiva e emocional desagradável, correlacionada a uma lesão tecidual real ou

Correspondente/Corresponding: Marcio Cajazeira Aguiar - Instituto de Ciências da Saúde - End: Av. Reitor Miguel Calmon, S/N, Canela Salvador - Ba, CEP: 40231-300-Tel: (71) 3283-8888 -E-mail: mcaguiar@ufba.br potencial, segundo a definição da Associação Internacional para o Estudo da Dor'1. A dor musculoesquelética é a queixa mais comum e consiste na principal causa de procura por atendimento médico e afastamento ocupacional pela população mundial. Dor miofascial é um termo empregado para descrever uma condição de dor muscular localizada, associada, muitas vezes, à existência 
de um ponto doloroso à palpação sobre uma área de músculo tenso e hiperativo, que pode se irradiar à distância, caracterizando uma dor referida. A dor miofascial pode acometer os músculos orofaciais, particularmente os músculos da mastigação, podendo fazer parte da síndrome da disfunção da articulação temporomandibular. Alguns fatores podem influenciar a doença, como o estresse emocional, o bruxismo, a má oclusão e as alterações estruturais da articulação temporomandibular (ATM)².

$\mathrm{Na}$ dor miofascial, o tratamento visa sanar ou amenizar o quadro doloroso a partir de estratégias conservadoras, à base de fármacos como analgésicos, anti-inflamatórios, relaxantes musculares, fisioterapia, laserterapia e uso de placas oclusais ${ }^{3}-5$. Uma anamnese e um exame clínico criterioso são essenciais para o estabelecimento de um diagnóstico e de tratamentos adequados.

Uma característica muito comum na dor miofascial é que, nem sempre, a dor relatada reflete a presença e (ou) extensão de uma lesão tecidual. É muito comum haver uma discordância entre os achados produzidos pelos exames de imagem e a condição clínica correspondente. Nas últimas décadas, a odontologia tem realizado estudos científicos a fim de subsidiar a escolha de intervenções mais adequadas em sua prática clínica. Um passo importante é a avaliação dessas condutas em estudos experimentais em animais, que podem atestar o benefício de algumas condutas no tratamento da dor miofascial ${ }^{6}$.

Uma opção para avaliação experimental dos tratamentos voltados para a dor miofascial é o teste de dor induzido pela carragenina lambda, associado ao teste de avaliação do limiar nociceptivo (teste de Von Frey). Os testes in vivo em ratos proporcionam comportamentos bem parecidos com o que acontece em humanos, no que diz respeito à percepção de dor e ao processo inflamatório. Além disso, outros benefícios correlacionados, como manuseio, maior controle do experimento e características parecidas em sua fisiologia e interações bioquímicas fazem com que os modelos animais sejam uma opção para o desenvolvimento de tratamentos para dor miofascial?.

A carragenina é um extrato de alga marinha que causa inflamação localizada quando inoculada em vários tecidos e tem sido usada em alguns modelos de dor inflamatória em animais como elemento indutor de dor ${ }^{8}$. Quando administrada no músculo, a carragenina produz uma resposta inflamatória aguda e rápida, aumentando a sensibilidade térmica e mecânica pela liberação de substâncias pró-inflamatórias, como bradicinina, histamina, taquimicina, oxigênio complementar e espécies de nitrogênio. Adicionalmente, pode promover edema, lesionar vasos sanguíneos, potencializar a endotoxidade e causar dor, além de recrutar neutrófilos e macrófagos para a área lesionada ${ }^{9,10}$.
A mensuração de dor nos ratos, após a aplicação da carragenina, pode ser analisada pelo teste de Von Frey, que permite medir os estímulos hiperalgésicos em tempos diferentes, diante de um protocolo estabelecido. Nesse teste, um analgesímetro eletrônico mede, em gramas, a quantidade de força necessária para causar uma reação de retirada da pata do roedor após a injeção de carragenina, quando comparada com a força necessária antes da injeção, sendo usada como uma medida de hiperalgesia para várias substâncias analgésicas e anti-inflamatórias ${ }^{11}$. Em pesquisas com animais, o teste de Von Frey permite avaliar a nocicepção associada à severidade do dano tecidual, sem a interferência de fatores biopsicossociais que poderiam ser desencadeantes e (ou) agravantes das dores de origem musculoesquelética ${ }^{12}$.

Sendo assim, com o intuito de propor o emprego desse instrumento diagnóstico na avaliação experimental da eficácia de terapias voltadas para o tratamento da dor miofascial orofacial, o presente estudo analisou a nocicepção causada pela carragenina em masseteres de ratos através do teste de avaliação do limiar nociceptivo (teste de Von Frey eletrônico), correlacionando-o com as alterações teciduais observadas no músculo masseter dos ratos, produzidas por essa droga inflamatória.

\section{METODOLOGIA}

\section{ANIMAIS}

Todos os procedimentos realizados nos animais foram aprovados pela Comissão de Ética no Uso de Animais (CEUA) do Instituto de Ciências da Saúde (ICS) da Universidade Federal da Bahia (UFBA) sob protocolo $n^{\circ} 133 / 2018$ (Anexo 1). Para o experimento, foram utilizados dez Ratus norvergicus, Albinos, Wistar, machos entre dois e três meses de idade, com massa corpórea de 170 a 240 gramas, os quais foram mantidos, durante o experimento, no Biotério do Laboratório de Neuro-imunoendocrinologia e Toxicologia, do ICS/UFBA. Durante todo o processo de experimentação, os ratos foram nutridos com ração solida peletizada (Nuvilab CR - 1, 20 - Kg Nuvital Agropecuária Ltda.) e hidratados ad libitum.

Após a aclimatação, os animais foram divididos aleatoriamente em dois grupos, sendo submetidos aos procedimentos experimentais, conforme se pode verificar na Figura 1. Após a anestesia com uma associação de cloridato de cetamina a $10 \%$ (Cetamin ${ }^{\circledast}$, Syntec), na dose de $100 \mathrm{mg} / \mathrm{Kg}$ e solução de $2 \%$ de cloridrato de xilazina (Sedanew ${ }^{\circledR}$, Vetnil) a $14 \mathrm{mg} / \mathrm{Kg}$, por via intraperitoneal, a região orofacial relacionada com os músculos masseteres direito foi tricotomizada. 
Figura 1 - Linha experimental.

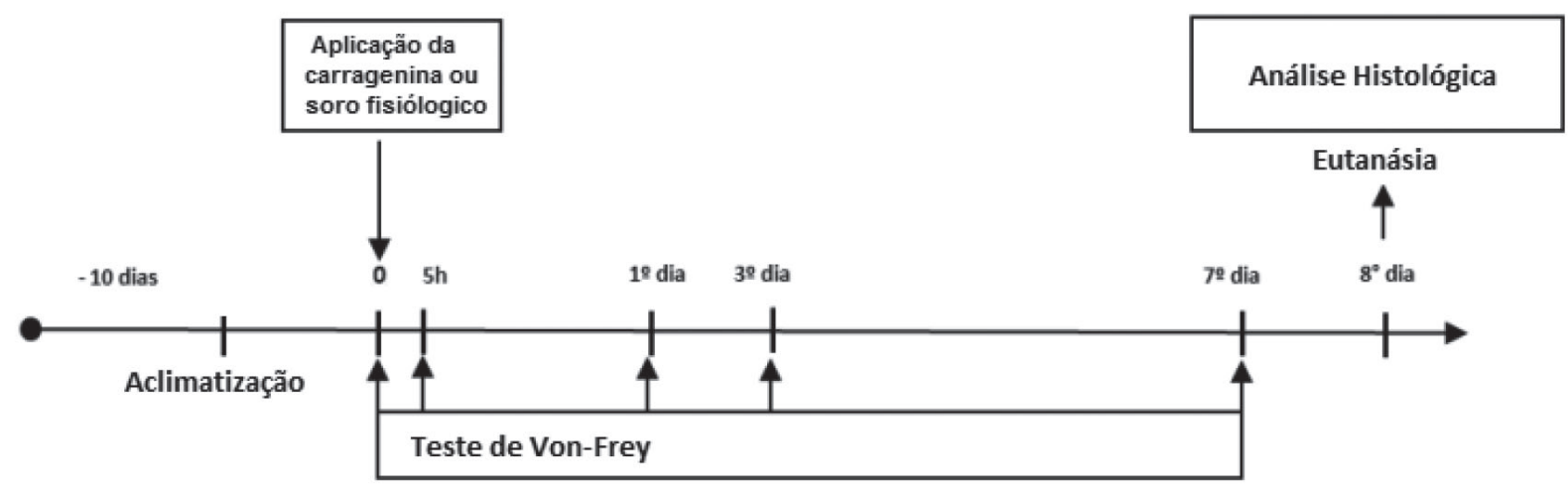

Fonte: Dados da pesquisa (2020).

\section{INDUÇÃO DA DOR INFLAMATÓRIA}

A dor inflamatória foi induzida por meio da aplicação de uma solução de $2 \%$ de carragenina lambda (type IV, Sigma Chemical Company, St. Louis USA) no músculo masseter direito dos animais. Em cada grupo, 50\% dos ratos receberam $100 \mu \mathrm{L}$ de uma solução de $2 \%$ de carragenina lambda (diluída em soro fisiológico), enquanto a outra metade foi tratada com $100 \mu \mathrm{L}$ de soro fisiológico. Em todas as infiltrações, foi utilizada uma seringa de insulina de $1 \mathrm{ml}$ acoplada a uma agulha $30 \mathrm{G}$.

A área de aplicação de soro fisiológico ou carragenina, na região orofacial sobrejacente ao masseter direito, foi um ponto de intersecção entre duas linhas imaginárias: uma horizontal de 1,5 cm, em continuidade à comissura labial para posterior, e outra vertical, formada no limite superior pelo ponto central da linha imaginária traçada da órbita e o trágus (região do músculo temporal), estendendo-se até $1 \mathrm{~cm}$ inferior.

\section{AVALIAÇÃO DA RESPOSTA NOCICEPITIVA}

A avaliação da resposta nociceptiva do músculo masseter de ratos foi adaptada a partir do método para avaliação da alodinia mecânica proposto por $\operatorname{Ren}^{13}$. Os ratos foram habituados a se manter eretos sobre as patas traseiras sobre uma superfície revestida por tecido de algodão, sempre apoiados pela mão protegida por uma luva de couro. A habituação dos animais foi realizada pela manipulação diária sempre por um mesmo operador.

A mensuração do limiar de retirada da cabeça foi executada com um analgesímetro digital de Von Frey (modelo EFF 301, Insight ${ }^{\circledR}$ ), antes da infiltração de carragenina ou soro fisiológico (basal) e 5 horas, 1, 3 e 7 dias após a aplicação das drogas experimentais, adaptada a partir da técnica descrita por Cunha ${ }^{14}$. Com base no fato de que sondas nociceptivas com o diâmetro maior ou igual a 1,6 mm refletem o limite de nocicepção mecânica em tecidos mais profundos, como os músculos ${ }^{15}$, a fim de evitar um estímulo cutâneo indesejável, a ponta metálica rígida do analgesímetro foi revestida por uma capa arredondada (diâmetro de $03 \mathrm{~mm}$ ), confeccionada previamente com resina acrílica autopolimerizável Duralay (Reliance Dental MFG. CO.).

A ponta foi pressionada gradualmente contra a superfície cutânea da área correspondente ao músculo masseter, perpendicularmente ao plano sagital, até o animal apresentar o reflexo de retirada da cabeça ou emitir um sinal fonético, havendo o registro automático em gramas da maior força aplicada. O limiar de retirada da cabeça de cada animal foi calculado como uma média de cinco medidas realizadas, com um intervalo entre as mensurações de 1 minuto. Para todos os protocolos, o examinador desconheceu o tratamento empregado em cada animal.

As médias de cada grupo e de cada período foram transformadas em percentuais estimados a partir das médias obtidas no tempo 0 ou seja, antes da carragenina (valor basal). As médias foram comparadas entre os dois grupos estudados.

\section{PROCESSAMENTO PARA MICROSCOPIA DE LUZ}

Após 8 dias da aplicação da carragenina ou do soro fisiológico nos masseteres, os animais foram eutanasiados com sobredosagem de uma associação de solução de cloridrato de cetamina $10 \%$ (Cetamin ${ }^{\circledR}$, Syntec) e solução de $2 \%$ de cloridrato de xilazina (Sedanew ${ }^{\circledR}$, Vetnil), via intraperitoneal. Em seguida, foi realizada a dissecação do masseter de forma a se obter a porção posterior do masseter profundo, a qual foi fixada em solução de $4 \%$ de formaldeído tamponado em fosfato de sódio $0,1 \mathrm{M}, \mathrm{pH}$ 7,4 , por 24 horas. Após fixação, os espécimes indicados para o estudo em microscopia de luz foram processados e corados para hematoxilina e eosina (H\&E), de forma a obter cortes semisseriados com $5 \mu \mathrm{m}$ de espessura, e transversais ao longo eixo do músculo masseter. 


\section{ANÁLISE HISTOLÓGICA}

As secções coradas com H\&E foram analisadas por um único observador e capturadas com auxílio de uma câmera digital (DP71, Olympus, Japão), acoplada a um microscópio de luz (modelo BX-51, Olympus, Japão), processado por um computador de mesa Pentium IV com auxílio do programa Image-Pro Plus ${ }^{\circledR}$ (Versão 6.2 - Media Cybernetics, USA). No estudo morfológico de todas as seç̧̃̃es, foram avaliadas as fibras musculares esqueléticas e os demais tecidos associados. Os resultados foram descritos observando-se a presença, a natureza e a intensidade da inflamação, o grau de vascularização, a espessura dos espaços perimisial e endomisial e o aspecto das células musculares esqueléticas (núcleo, integridade do sarcoplasma, espessura das fibras e acidofilia), em função da presença do soro fisiológico e da carragenina.

\section{ANÁLISE ESTATÍSTICA}

Os resultados, expressos como média \pm erro padrão da média (e. p. m.), foram testados quanto à normalidade através dos testes de Shapiro-Wilk e Kolmogorov-Smirnov. As análises estatísticas foram feitas utilizando-se o teste de Anova-Two Way, seguido de pós- -teste de Tukey. Valores de $p<0,05$ foram considerados significantes.

\section{RESULTADOS}

\section{AVALIAÇÃO DO LIMIAR DE RESPOSTA NOCICEPTIVA}

O estudo comparativo entre os dois grupos evidenciou diferenças importantes na resposta nociceptiva, algumas delas estatisticamente significantes, que estão descritas a seguir.

No grupo de controle, a administração de soro fisiológico resultou em pequenas alterações do percentual de variação do limiar nociceptivo em relação ao valor basal. Contudo, as oscilações percentuais não foram estatisticamente significantes quando os tempos experimentais foram comparados dentro do mesmo grupo $(p>0,05)$.

No grupo tratado com a carragenina, foram observadas alterações importantes no percentual de variação do limiar nociceptivo, particularmente no período de 5 horas após a aplicação da droga. Nesse período, houve uma redução do limiar nociceptivo de 2,5 vezes em relação ao grupo tratado com soro fisiológico, sendo o resultado estatisticamente significante $(p<0,01)$ (Figura 2).

Figura 2 - Efeito do soro fisiológico e da carragenina administrados no masseter sobre o percentual de variação do limiar de resposta nociceptiva mecânica em relação ao valor basal mensurado com analgesímetro digital de Von Frey.

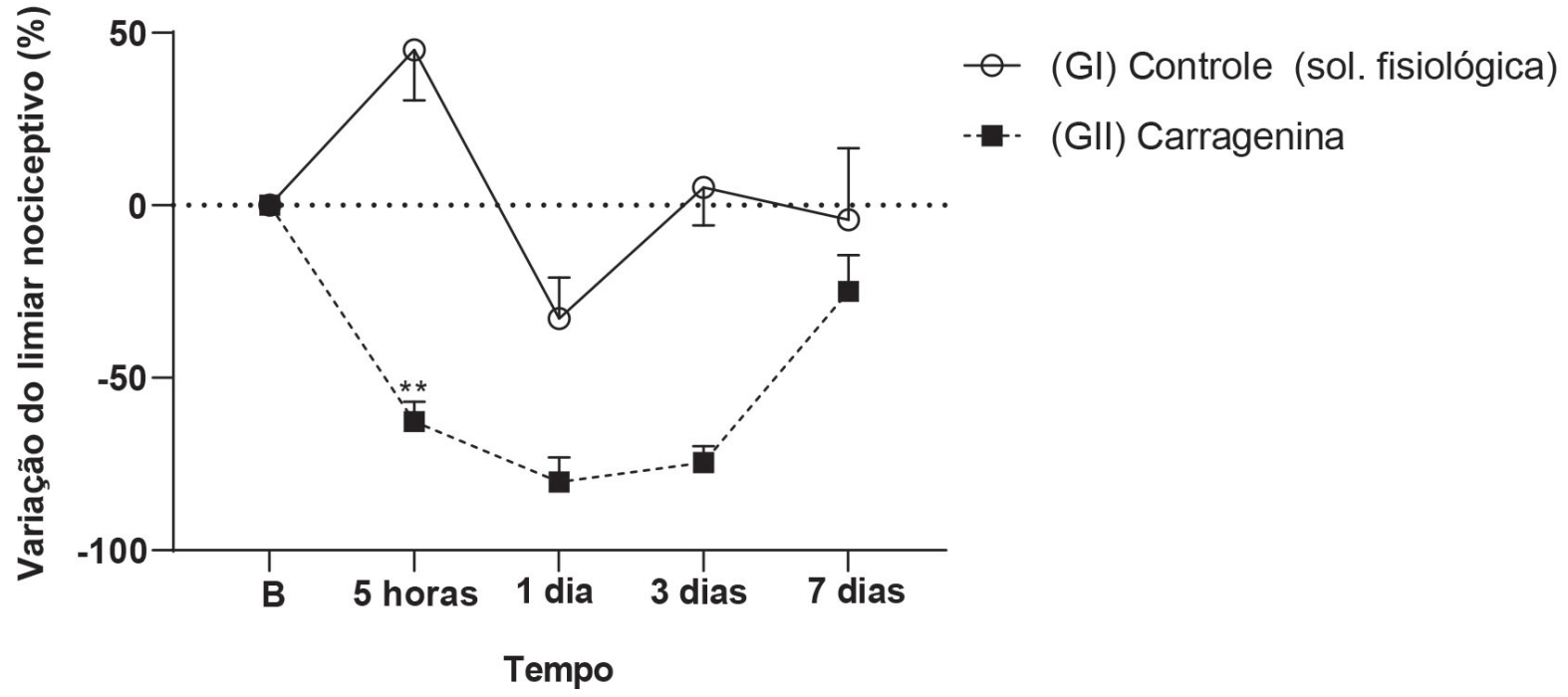

Fonte: Dados da pesquisa (2020).

Legenda:** $p<0,01$ em comparação com o grupo Gl (soro fisiológico) para o mesmo tempo (ANOVA two-way, pós-teste de Tukey). Observar diminuição do valor percentual de resposta nociceptiva no tempo experimental de 5 horas no grupo Gll, quando comparado ao do grupo $\mathrm{Gl}(p<0,01)$.

\section{ACHADOS HISTOLÓGICOS}

$\mathrm{Na}$ avaliação morfológica, as características da matriz extracelular e das células do músculo masseter tratado com soro fisiológico ou carragenina foram descritas e comparadas.
Nas amostras do grupo tratado com soro fisiológico, em seç̧ão transversal, as fibras musculares do masseter mostravam aspecto poliédrico, com um espaço endomisial pouco perceptível (Figura $3-A$ ) O espaço perimisial estava preenchido por tecido conjuntivo formado por fibroblastos, fibras colágenas tipo I e vasos sanguíneos. Em 
algumas amostras, foi observada uma área de aspecto linear e bastante celular, associada com a destruição de algumas células musculares esqueléticas, provavelmente relacionadas à penetração da agulha hipodérmica no músculo masseter (Figura $3-B$ ).

No grupo tratado com a carragenina, os masseteres apresentaram algumas áreas focais de moderada à intensa destruição de fibras musculares esqueléticas, com aumento dos espaços endomisial e perimisial (Figura $3-\mathrm{C}$ ). O espaço perimisial estava preenchido por um tecido muito celular, contendo alguns linfócitos, muitos macrófagos e raros mastócitos (Figura 3-D).

Figura 3 - Fotomicrografias com seç̧ões transversais das fibras do músculo masseter direito de ratos.
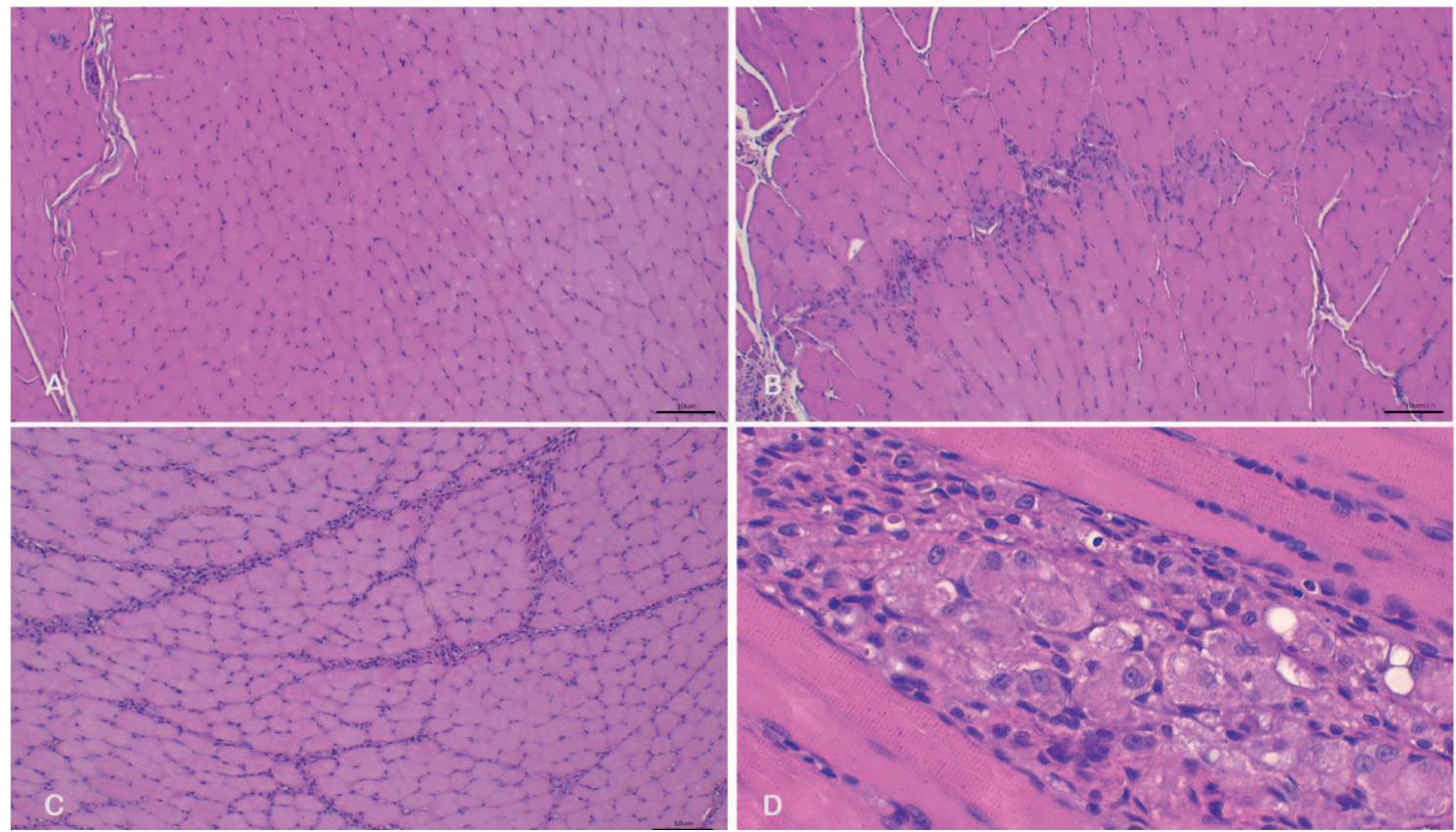

Fonte: Dados da pesquisa (2020).

Legenda: *Infiltrado com soro fisiológico ( $A$ e B) e com carragenina (C e D) no período de 8 dias após a intervenção. Note-se a presença de fibras musculares esqueléticas acidófilas e bem conservadas, circundadas por um espaço endomisial nos grupos tratados com soro fisiológico, exceto pela presença de uma área linear e ondulada entre os grupos de fibras musculares, provavelmente relacionadas com uma lesão mecânica provocada pela introdução da agulha. Em comparação com o grupo de controle, observe-se que o grupo tratado com carragenina exibiu um alargamento dos espaços endomisiais e perimisiais que estavam preenchidos por um tecido bastante celularizado, com poucas fibras colágenas. Coloração $H \& E$.

\section{DISCUSSÃO}

O presente estudo mostrou que o modelo de dor inflamatória induzido pela carragenina, associado ao teste de Von Frey, foi capaz de detectar pequenas modificações na sensibilidade dolorosa em função dos períodos estudados, constituindo-se numa alternativa para a avaliação experimental de drogas antinociceptivas ou anti-inflamatórias em condições dolorosas nos músculos da região orofacial, especialmente no músculo masseter. Neste estudo, a carragenina reduziu o limiar nociceptivo nos animais tratados com essa droga, além de causar uma alteração tecidual localizada associada a um processo inflamatório crônico, 8 dias após a intervenção terapêutica.

Muitos modelos animais de dor utilizam a estratégia de injetar drogas irritantes na pele, na pata, nos músculos e nas articulações para produzir dor inflamatória aguda, associada ao recrutamento de neutrófilos ou respostas nociceptivas mais duradoras, com a participação dos macrófagos. Dessa forma, tais modelos são utilizados para simular condições de inflamação aguda ou crônica, a fim de validar a eficácia de muitas drogas como os opioides e os anti-inflamatórios não esteroi$\mathrm{des}^{12}$. Dentre elas, a carragenina é uma droga que vem sendo utilizada há muitos anos na área da medicina experimental, constituindo-se em um polissacarídeo capaz de gerar uma reação inflamatória tecidual em patas de ratos e articulação do joelho ${ }^{10,16,17}$.

A inflamação gerada por drogas gera alodinia e hiperalgesia, que podem ser mensuradas por testes mecânicos. Um teste comum em roedores para medir nocicepção é o teste de Von Frey. É um teste muito útil para simular condições clínicas com sensibilidade cutânea aumentada ${ }^{12}$. No presente estudo, a ponta metálica rígida do analgesímetro foi revestida por uma capa arredondada (diâmetro de $3 \mathrm{~mm}$ ), confeccionada com resina acrílica autopolimerizável, pois sondas nociceptivas com o diâmetro maior ou igual a 1,6 $\mathrm{mm}$ podem refletir o limite de nocicepção mecânica em tecidos mais profundos, como os músculos $^{13}$. Na década de 80 , a técnica foi 
modernizada, sendo realizada atualmente por meio de um analgesímetro eletrônico, que mede digitalmente a força em gramas exercida por uma caneta com uma ponta sobre a área afetada. As modificações nos limiares nociceptivos são detectadas exercendo-se uma pressão linearmente crescente no centro da pata estimulada, até a produção de uma resposta caracterizada como sacudida (flinches) ${ }^{18,19}$. Em nosso estudo, o teste de Von Frey foi proposto para testar a sua sensibilidade na mensuração da dor orofacial, especialmente nas dores musculares. Os achados observados no presente estudo indicam que o teste de Von Frey foi capaz de detectar diferenças na nocicepção em função dos grupos e dos períodos de análise.

Em nosso modelo, o teste de Von Frey pareceu ser mais sensível em alguns períodos específicos. 0 teste realizado no músculo masseter indicou uma diminuição do limiar da resposta nociceptiva em todos os períodos no grupo tratado com carragenina, quando comparado com o grupo de controle, mas a diferença entre os grupos foi estatisticamente significante apenas no período de 5 horas. $O$ presente achado também foi observado no trabalho de Serra e Ashmawi ${ }^{20}$, que avaliaram a influência da naloxona e da metisergida sobre o efeito analgésico do laser em baixa intensidade em um modelo experimental de dor. Em seu trabalho, o efeito analgésico do laser InGaAIP sobre a nocicepção provocada pela carragenina na pata posterior de ratos foi melhor evidenciado no último período estudado (4 horas). Tais evidências indicam que o período entre $4 \mathrm{e}$ 5 horas seria o mais adequado para a comparação do efeito de drogas sobre a dor induzida experimentalmente pela carragenina e avaliada pelo método Von Frey nos músculos orofaciais.

Os achados observados contraindicam o emprego da associação da dor induzida pela carragenina com o método Von Frey para o estudo da eficácia de drogas anti-inflamatórias e analgésicas em voluntários humanos, pois todos os espécimes tratados com carragenina mostraram áreas de destruição tecidual de grau moderado a severo. A lesão tecidual pode ser atribuída ao intenso processo inflamatório produzido pela carragenina. O processo inflamatório induzido por essa droga tem sido bastante estudado no modelo de dor inflamatória nas patas de roedores. $O$ desenvolvimento de edema em pata traseira de rato após a injeção de carragenina, por exemplo, é resultado da ação de vários mediadores inflamatórios que agem sequencialmente para produzir uma resposta inflamatória. Na fase inicial da inflamação gerada pela carragenina, observa-se o aparecimento do edema pela ação da histamina, da serotonina e da bradicinina, enquanto as prostaglandinas, especialmente do tipo $E$, estão presentes na fase tardia da inflamação. Algumas citocinas pró-inflamatórias como a TNF- $\alpha$, IL-1 e IL-6 também podem estar presentes, estando relacionadas com uma inflamação local e (ou) sistêmica. A inflamação é maximizada pela infiltração e ativação de neutrófilos que secretam muitos mediadores, como o ânion superóxido, um radical livre derivado de oxigênio ${ }^{16}$. Portanto, essa estratégia está indicada apenas para o estudo experimental da eficácia de drogas em tecido muscular em modelos animais.

Em nosso modelo, a análise histológica dos espécimes do grupo tratado com a carragenina mostrou a presença de espaços perimisial e endomisial alargados e preenchidos por uma matriz bastante celular, contendo alguns linfócitos, muitos macrófagos e raros mastócitos. Tais achados não condizem com o quadro histológico compatível com inflamação aguda descrita tradicionalmente em patas de roedores infiltradas com carragenina. A diferença pode estar relacionada com o período experimental (8 dias) selecionado para eutanásia no presente estudo. Decorridos 8 dias da administração da carragenina, provavelmente, o processo inflamatório agudo com pico em 4 horas após inoculação da droga inflamatória e caracterizado por vasodilatação, aumento da permeabilidade e migração de leucócitos polimorfonucleares, foi convertido em um processo inflamatório crônico, com infiltração de células mononucleares. Tais achados histológicos correlacionaram-se com o estudo de Radhakrishnan, Moorec e Sluka ${ }^{10}$, que avaliaram o padrão inflamatório gerado pela infiltração de carragenina na articulação do joelho e no músculo gastrocnêmio em ratos nos tempos experimentais de 4, 8, 24 horas, e 1, 2, 4 e 8 semanas após a aplicação dessa droga. Os achados histológicos apresentados aqui indicam a necessidade de se estudarem o dano tecidual e o processo inflamatório nas primeiras 24 horas após a aplicação da carragenina, a fim de observar sua ação sobre os períodos iniciais, no modelo de dor inflamatória estudado.

O modelo de dor inflamatória a partir da carragenina aplicada ao masseter de ratos pode ser utilizado para testes farmacológicos ou terapias para o tratamento de condições dolorosas da região orofacial, permitindo, por exemplo, a criação de drogas direcionadas aos pacientes com dor miofascial, como também pode ser utilizado por diversos profissionais para desenvolver terapias e protocolos que envolvam a laserterapia, a ozonioterapia e a fisioterapia ${ }^{2,21,22}$.

\section{CONCLUSÕES}

O presente trabalho foi o primeiro estudo a avaliar a sensibilidade de um modelo de inflamação mediado pela carragenina associado ao método Von Frey no músculo masseter de ratos. Os resultados apresentados aqui revelaram que o método Von Frey foi capaz detectar alterações na nocicepção entre os grupos tratados com carragenina ou com soro fisiológico, ainda que a diferença estatisticamente significante entre ambos os grupos tenha ocorrido apenas em alguns períodos específicos. Os resultados mostrados indicam que a associação de uma droga inflamatória com o método Von Frey pode ser uma ferramenta sensível para analisar o efeito de 
terapias ou drogas sobre a dor miofascial. Contudo, não se recomenda seu emprego em estudos com seres humanos, visto que produz dano tecidual, estando indicada apenas para estudos experimentais em animais. Nossos achados devem ser confirmados por outros trabalhos experimentais empregando outros modelos de inflamação e dor associados ao método Von Frey, com o propósito de confirmar os efeitos benéficos dessa ferramenta para a análise das condições dolorosas do músculo masseter e dos demais músculos.

\section{REFERÊNCIAS}

1. COHEN, M.; QUINTNER, J.; VAN RYSEWYK S. Reconsidering the International association for the study of pain definition of pain. Pain Rep., Philadelphia, v.3, n.2, p. e634, Mar. 2018.

2. De MORAES MAIA M.L. et al. Evalution of low-level laser therapy effectiveness on the pain and masticatory performance of patients with myofascial pain. Lasers Med. Sci., London, v.29, n.1, p.29-35, Jan 2014.

3. BATISTA, J.S.; BORGES A. M.; WIBELINGER, L. M. Tratamento fisioterapêutico na síndrome da dor miofascial e fibromialgia. Rev. Dor, São Paulo, v.13, n.2, p.170-174, abr./ jun. 2012.

4. ALTINDIS, T.; GÜNGÖRMÜS, M. Thermographic evaluation of occlusal splint and low level laser therapy in myofascial pain syndrome. Complement Ther. Med., Edinburgh, v.44, p. 277-281, 2009.

5. YOMASA, M.M. et al. Zymographic and ultrastructural evaluations after low-level laser irradiation on masseter muscle of HRS/J strain mice. Lasers Med. Sci., London, v.28, n.3, p.777-783, May 2013.

6. SANTOS, L.F.S.; PEREIRA, M.C.A. A efetetividade da terapia manual no tratamento de disfunção temporomandibulares (DTM): uma revisão de literatura. Rev. Aten. Saúd, [s.I], v.14, v.49, p.72-77, jul./set 2016.

7. GATCHEL, R. J. et al. Efficacy of an early intervention for patients with acute temporomandibular disorder-related pain: a one-year outcome study. J. Am. Dent. Assoc., Chicago, v.137, n.3, p.339-47, 2006.

8. KEHL, L.; FAIRBANKS, C.A. Experimental animal models of muscle pain and analgesia. Exerc. Sport Sci. Rev., New York v.31, n.4, p.188194, Oct 2003 Oct .

9. MORRIS, C. J. Carrageenan-Induced Paw Edema in the Rat and Mouse. In: WINYARD, P. G.; WILLOUGHBY, D. A. Inflammation protocols. Totowa, NJ: Humana Press, 2013. p. 115-121.
10. RADHAKRISHNANA R, MOOREC S. A, SLUKA K. A. Unilateral carrageenan injection into muscle or joint induces chronic bilateral hyperalgesia in rats. Pain, Amsterdam, v.104, n.3, p.567-577, Aug. 2003.

11. SILVA, J.C. et al. Modelos experimentais para avaliação da atividade antinociceptiva de produtos naturais: uma revisão. Rev. Bras. Farm., v.94, n.1, p.18-23, 2013

12. GREGORY, N. S. et al. A. An overview of animal models of pain: disease models and outcome measures. Rev. Elsevier, [s.I], v.14, p.11, p.1255-1269, Nov. 2013.

13. REN, K. An improved method for assessing mechanical allodynia in the rat.Physiol Behav., Elmsford, v.67, n.5, p.711-716, Nov 1999.

14. CUNHA, T. M. et al. An electronic pressure-meter nociception paw test for mice, Braz J. Med. Biol. Res., Ribeirão Preto, v. 37, p.401-407, 2004.

15. TAKAHASHI, K. et al. Influence of surface anesthesia on the pressure pain threshold measured with differentsized probes. Somatosens Mot. Res., Abingdon, v.22, n.4, p.299-305, Dec. 2005.

16. NECAS, J.; BARTOSIKOVA, L. Carrageenan: a review. Vet. Med., Praha, v.58, n.4, p. 187-205, 2013.

17. FAVRE-GUILMARD, C.; CHABRIER, P. E.; KALINICHEV, M. Bilateral analgesic effects of botulinum toxin A (Dysport ${ }^{\circledR}$ ) following unilateral administration in the rat. Eur. J. Pain, London, v.21, n.5, p. 927-937, May 2017.

18. GATCHEL, R.J. et al. Efficacy of an early intervention for patients with acute temporomandibular disorder-related pain: a one-year outcome study. J. Am. Dent. Assoc., v.137, n.3, p.339-347, Mar 2006.

19. GRAVA, A.L.S, et al. Modelo experimental para o estudo da hérnia do disco intervertebral. Rev. Bras. Ortop., São Paulo, v.43. n.4, p. 117-125, abr. 2008

20. SERRA, A.P; ASHMAWI, H.A. Influência da naloxona e metisergida sobre o efeito analgésico do laser em baixa intensidade em modelo experimental de dor. Campinas. Rev. Bras. Anestesiol., Rio de Janeiro, v.60, n.3, p. 302-305, maio/jun. 2010

21. ATARAN, R. et al. The role of botulinum toxin A in treatment of temporomandibular joint disorders: a review. J. Dent. Shiraz Univ. Med. Sci., [s.I], v.18, n.3, p.157-159, Sept. 2017.

22. KIM, S. Y. et al. Treatment of non-odontogenic orofacial pain using botulinum toxin-A: a retrospective case series study. Maxillofac. Plast. Reconstr. Surg., Seoul, v. 40, n.1, p.21, Dec. 2018.

Submetido em: 19/11/2020

Aceito em: 23/11/2020 